\title{
A ATUAÇÃO DO PSICÓLOGO JUNTO À DEFESA CIVIL NO ESTADO DE SANTA CATARINA: UMA REVISÃO
}

\author{
THE PERFORMANCE OF THE PSYCHOLOGIST TO THE DEFENCE IN SANTA \\ CATARINA STATE: A REVIEW
}

Kézia Rodrigues Sipriano

Elenice de Freitas Sais

Endereço eletrônico para contato: - kezzia07@hotmail.com

\section{RESUMO}

O presente artigo fala sobre a atuação do psicólogo frente às situações de emergências e desastres. Foram utilizadas as acepções sobre emergências e desastres e atuação do psicólogo nestes casos à luz do Conselho Federal de Psicologia. Já a compreensão teórica também buscou compreender o papel da Defesa Civil e suas ações à nível nacional frente às situações de desastre e emergência e conhecer se o psicólogo encontra-se atuando junto a esta. Como resultados pode se apontar que não existe a obrigatoriedade legal da presença do psicólogo atuando junto a Defesa Civil. Para tanto o Sistema Conselhos, do Conselho Federal de Psicologia, publicou uma nota técnica auxiliando os psicólogos a buscarem juntamente com a população, em especial, a população afetada a relevância de ter um profissional de psicologia atuando junto a defesa civil tanto na prevenção quanto na resposta ao pós desastre.

Palavras - chave: Psicologia, Emergência, Desastre, Defesa Civil.

\begin{abstract}
This article discusses the role of the psychologist in situations of emergencies and disasters. the meanings of the Civil Defense will be cited, observing the hierarchy of the members of bodies at national level, will also be presented the resolutions of the Federal Council of Psychology in order to understand concepts about emergencies and disasters as well as the introduction of Psychology front of such a situation. His focus is on the psychologist in the various areas that make up the situation of emergencies and disasters, among them prevention, preparedness, response and reconstruction.
\end{abstract}


Keywords: Psychology, Civil Defense, Emergency, Disaste

\section{INTRODUÇÃO}

É sabido que nosso planeta vem sofrendo com mudanças climáticas, e tais fenômenos afetam diretamente a vida das pessoas; porém, nunca estamos preparados para tais eventos.

Mesmo com acesso à tecnologia e as informações chegam rápido ao alcance da população os piores desastres ambientais da história, já registrados, foram aqueles em que a população, não estava esperando. Num momento estão vivendo a vida e o cotidiano de forma natural e num instante depois, tudo se torna em um terrível pesadelo, projetos e sonhos, em questão de minutos toda uma história de vida muda pra sempre e são interrompidos.

Em 2013 o portal Joinville publicou que Santa Catarina está entre os estados brasileiros mais atingidos por desastres ambientais. Ainda cita que entre os desastres que mais atinge a população estão a seca, estiagens, enxurradas e enchentes ${ }^{1}$. No portal de notícias G1, o jornal relembra os dez anos após o furacão Catarina, ocorrido em março de 2004, onde deixou mais de 27,5 mil desalojados, quase 36 mil casas danificadas, 518 feridos e 11 mortos $^{2}$.

No Atlas de Desastres Naturais do Estado de Santa Catarina, o nosso estado está sendo palco de uma variada gama de desastres naturais, tempestades e inundações têm causado grandes estragos, tanto para a população que sofre com as perdas de bens materiais e danos psicológicos, quanto à economia do estado 3 .

Estes fenômenos, além de causar danos materiais às famílias atingidas, também causam danos psicológicos. De acordo com o DSM IV ${ }^{4}$, o transtorno de estresse pós-traumático é caracterizado pelo desenvolvimento de um conjunto de sintomas em decorrência de o portador ter sido vítima ou testemunha de um evento real ou ameaçador que envolve morte ou sério ferimento. Estes eventos podem estar relacionados a combate militar, agressão física, sequestro, ataque terrorista, tortura, desastre naturais ou causados pelo homem, graves acidentes automobilísticos ou receber o diagnóstico de uma doença que traz risco de vida 4 . 
Pensando a nível nacional, quanto à atuação do psicólogo, buscou-se entender qual seria a ação deste junto à Defesa Civil. Assim, para a composição do presente artigo, foi realizada uma revisão bibliográfica, em livros, artigos científicos, documentos publicados pelos órgãos oficiais do Brasil como a Defesa Civil e divulgações dos Conselhos Regionais e Federal de Psicologia.

Com a finalidade de esclarecer e aprofundar os conhecimentos, o objetivo do presente artigo será compreender o papel do psicólogo frente às situações de Emergência e Desastre segundo as prerrogativas que regulamentam a sua profissão.

\section{A PSICOLOGIA NA SITUAÇÃO DE EMERGÊNCIAS E DESASTRES}

A psicologia na situação de emergências e desastres tem levantado várias questões sociais, políticas e muitas dúvidas quanto ao papel do psicólogo e suas contribuições.

É sabido que eventos ambientais têm causados danos tantos sociais como econômicos, e diante de tais acontecimentos a psicologia como ciência, que busca compreender o comportamento humano, tem voltado seus estudos e pesquisas para cuidar das pessoas que sofrem com tais perdas, sendo afetadas não só fisicamente ou materialmente, mas também emocionalmente. No que se refere a saúde mental e emocional dessas pessoas a psicologia vem desenvolvendo estudo para melhor atender as vitima dessas catástrofes.

De acordo com o psicólogo Molina ${ }^{5}$, o tema da Psicologia de Emergências e Desastres vem adquirindo cada vez mais interesse por conta dos últimos acontecimentos com o planeta.

Quando ocorre a destruição de uma cidade, esta se encontra na categoria de danos materiais, portanto, não se pode rejeitar a perda de danos emocionais, como a perda da segurança, da dignidade, do cotidiano que organiza o comportamento, do senso de permanecer em uma cidade ${ }^{6}$.

Com relação aos desastres, os psicólogos estão fazendo parte da resposta posterior a um desastre, isso significa que esses profissionais começam a ficar inquietos na busca por algum tipo de formação especializada neste âmbito, e esta 
busca geralmente se dá por saber da necessidade que a população tem de receber um suporte emocional diante de um evento traumático.

Para que a psicologia enquanto ciência possa contribuir para a saúde mental dessas pessoas que passam por situação de desastre ou emergência,não importa a abordagem do profissional ou sua área de atuação, todo psicólogo pode estar habilitado para trabalhar. De acordo com Franco (2015), quando se trata de uma catástrofe natural, sabemos que cada caso tem sua característica, mas o profissional da psicologia precisa estar disponível para dar o seu melhor a população naquele momento, mesmo que o próprio profissional faça parte da mesma comunidade atingida.

De maneira geral, sem exceções, o objetivo do atendimento psicológico é resolver situações de grandes pressões, em um período reduzido e com uso de intervenção direta e focalizada por meio de instrumentos que a psicologia dispõe, para que os atingidos possam desenvolver novas estratégias adaptativas ${ }^{6}$.

Para que se possa melhor compreender a atuação do psicólogo na situação de desastre, a mesma tem sido estudada pela psicologia em dois campos específicos: Na Psicologia Ambiental e na Psicologia das Emergências e dos Desastres.

A primeira enfatiza o quanto o ambiente e o indivíduo são influenciados um pelo outro.

A psicologia ambiental surge no século $X X$ com o campo da psicologia e da ecologia. Em 1924 foi publicado o manual de métodos biológicos, por Hellpache, tendo influência de Lewin ${ }^{7} \mathrm{com}$ a teoria de campo, ela busca o significado simbólico dos espaços, o psicossocial, as interações, pois a paisagem em psicologia é ligada ao mundo intrapsíquico, enquanto na geografia e na arquitetura é no mundo externo, ou seja, são "olhares" diferentes.

Assim a identidade de lugar é um componente específico do próprio "eu" do sujeito, são sentimentos, valores, crenças, pensamentos conscientes e inconscientes que fazem parte da vida íntima de cada indivíduo e isso se dá também relacionado ao lugar onde o mesmo habita ${ }^{8}$.

Dessa forma, o sujeito cria o seu processo a apropriação daquele espaço (casa ou cidade). Em sua obra "Cidade e Poética", fala sobre o indivíduo que ao instalar-se numa casa vazia, ele vai se apropriando do espaço e o espaço dele, e ao 
decorar cada detalhe da sua casa a pessoa está deixando ali sua marca, seu modo de agir e sentir, sua identidade pessoal. Portanto, pode-se dizer que quando uma pessoa perde tudo numa situação de desastre, ela perdeu parte de sua identidade.

E a psicologia das Emergências e dos Desastres que busca formas de trabalhar com os indivíduos, avaliando os impactos psicológicos, bem como no trabalho preventivo e de auxílio às vítimas diretas e indiretas. ${ }^{6,9-13}$

\section{A ATUAÇÃO DO PSICÓLOGO FRENTE À SITUAÇÕES DE DESASTRES.}

Em dezembro de 2006, segundo informações do site do Conselho Federal de Psicologia,com a realização do Seminário Nacional de Psicologia pode se reafirmar a importância da atuação do psicólogo na área de emergências e desastres, onde,começaram as buscas por ampliar o conhecimento para a atuação do profissional de psicologia nesta área.

De acordo com as normas e resoluções do Conselho Federal de Psicologia, é de extrema importância que o psicólogo respeite o protagonismo social das pessoas afetadas sem que seja promovida a vitimização ou patologização, evidenciando, em primeiro lugar, a garantia de seus direitos.

O Conselho Federal de Psicologia que rege as normativas para a regularização do profissional de psicologia, elaborou uma nota técnica para orientar o trabalho que os psicólogos realizam nessas situações de emergências e desastres. Seja o psicólogo contratado para realizar tal tarefa ou um voluntário, ele estará submetido ao código de ética e terá que estar ativo no registro do Conselho Regional de Psicologia (CRP) da sua área de jurisdição.

Em decorrência as situações de emergências e desastres em que estamos vivenciando, o Sistema Conselho Federal de Psicologia reconhece a necessidade de órgãos públicos e privados estarem preparados para prestar o serviço a população afetada. E para que a resposta imediata a tais ocorrências seja feita de forma eficaz, é necessário que os serviços de rede pública, especialmente a defesa civil articulem planos de ação e grupos preparados para este atendimento, para evitar ações improvisadas. 
como já foi citado o campo da psicologia em desastres é recente e tem como focos a saúde mental e as necessidades psicossociais de pessoas afetadas por catástrofes ${ }^{6}$.

Os objetivos do trabalho diante do sinistro são: evitar maiores danos, aliviar o sofrimento imediato e dar apoio efetivo para seu enfrentamento, assim, para que se realize tais expectativas, é necessário ações que sejam preventivas, sensíveis e progressivas.

Distingue as atividades recomendadas nos diferentes níveis de resposta aos desastres. Os níveis identificados são: preparação, mitigação/prevenção (o que fazer para ser proativo e prevenir problemas durante a resposta ao desastre), resposta (o que fazer quando a resposta propriamente tem início), recuperação e gerenciamento das consequências (após a resposta), sobrevivência de quem atuou no desastre. Para isso foi citada algumas habilidades indispensáveis como: Treinamento para intervenção em crises geradas pelos desastres;ensino sobre resposta a desastres para membros da equipe; triagem psicossocial; coleta de informação entre a equipe; treinamento para ressuscitação cardiopulmonar ${ }^{12,6}$.

A atuação do psicólogo vai muito além de oferecer conforto emocional e técnicas para alívio imediato do sofrimento, para trabalhar com os atingidos na prevenção de transtornos mentais e no fortalecimento de suas redes de apoio e de ações de cidadania ${ }^{6}$.

No Segundo Seminário Nacional de Psicologia em Emergências e desastres, publicado pelo Conselho Federal de psicologia ${ }^{14}$, para os autores as intervenções psicológicas adotadas para a assistência às pessoas têm enfocado a fase da resposta, ou seja, pouca atenção tem sido dada à prevenção e à preparação quanto a emergências e desastres.

A forma de aplicar a Psicologia a esses fenômenos, deve ser compreendida de maneira distinta conforme as diferentes especialidades ${ }^{5}$. Na realidade, podemos identificar que o perfil do psicólogo costuma relacionar-se à etapa da emergência na qual ele intervém. Ao compreender a emergência como fenômeno eminentemente social, entende-se que a Psicologia pode dar sua contribuição em diferentes linhas de intervenção ${ }^{5}$. 
Santos e Mello ${ }^{15}$, nos trazem uma reflexão sobre a ação da psicologia das emergências e desastres junto a defesa civil; a grande maioria da população acredita que em decorrência de um desastre é feita a solicitação para que o profissional de psicologia possa estar atuando, porém, o foco do trabalho desses agentes está voltado para a prevenção.

O Conselho Federal de Psicologia recomenda que o profissional leve em consideração o compromisso ético da profissão e planeje ações estratégicas que envolvam a participação da sociedade e grupos de apoio com as pessoas que sofreram algum tipo de dano durante a situação de desastre ${ }^{13}$.

Segundo a Dra. Ângela Elizabeth Lapa Coelho ${ }^{15}$ que atua na área da psicologia social, as ações realizadas junto à sociedade são extremamente importantes e sempre que um psicólogo tem a oportunidade de trabalhar em órgãos públicos deve promover a saúde. No caso de emergências e desastres o melhor trabalho a ser feito é a prevenção.

Diante das afirmações citadas acima, percebemos a importância da psicologia social na atualidade, principalmente nos trabalhos de prevenção e promoção da saúde mental.

O psicólogo ainda é visto como um psicólogo clínico. Ele ainda afirma que existem várias formas de clínicas, no entanto, a maioria está se referindo ao atendimento individual, isto é, o psicólogo dentro de um consultório com seu paciente,a impressão que se tem e que ainda aparece é que, para ajudar uma pessoa a sair da crise é indispensável um "setting" terapêutico ${ }^{17}$.

A psicologia social aborda as interações entre os membros de um grupo social, busca compreender como o homem se comporta nas suas relações sociais. Conforme Lane ${ }^{19}$ a psicologia social estuda o comportamento de indivíduos no que ele é influenciado socialmente. Sendo que isto acontece desde o momento que nasce, ou mesmo antes do nascimento, enquanto condições históricas que deram origem a uma família, a qual convive com certas pessoas.

Desta forma, a Psicologia Social como área de conhecimento, passa a estudar o psiquismo humano, sendo este o objeto de estudo da Psicologia, que busca compreender como se dá a construção desse mundo interno a partir das relações vivenciadas pelo homem. 
O mundo objetivo passa a ser visto não como fator de influência para o desenvolvimento da subjetividade, mas como fator constitutivo ${ }^{19}$.

De acordo com Bruck ${ }^{17}$, essa prática descaracteriza o foco das necessidades pessoais e institucionais como o Pronto Socorro, Serviço de Atendimento Móvel de Urgência ou Hospitais. As instituições citadas são serviços que mais prestam atendimento de emergência. $\mathrm{E}$ o que Bruck ${ }^{17}$ pode perceber durante sua pesquisa, é que as pessoas que estão lidando com as situações de emergências e desastres não estão preparadas para lidar com o caos de forma humanitária.

Quando acontece uma situação de emergência as equipes de pronto atendimento, estão esperando a equipe de saúde mental, como uma equipe treinada e organizada, para saber o que fazer mediante a tais situações ${ }^{6}$.

A equipe de saúde deve dar suporte emocional durante o período agudo que se segue a um desastre. Isso ajudaria as vítimas a entenderem e até a uma da melhora ansiedade gerada pelo desastre e a compreensão das reações de luto 6 .

O plano de ação de acordo com Santos e Mello ${ }^{15}$, refere-se a ação direta, que significa o atendimento às vítimas onde ocorreu a emergência. Este primeiro atendimento seria uma escuta atenta, entrevista de apoio, ou até mesmo para ser um portador de informações, com objetivo principal de manter as pessoas situadas e orientadas diante do caos.

A psicologia ainda não tem um estudo um modelo padrão para trabalhar nesta área. Desse modo, o objeto de estudo é sobre a visão de homem. Ou seja, na situação de desastres o principal foco seria minimizar os danos psicológicos atuando de maneira a resgatar o equilíbrio mental e emocional do indivíduo ${ }^{20}$.

A avaliação cognitiva pode ser incluída como um método de classificação, quando se trata de um evento traumático, a seleção advém de acordo com o bemestar das pessoas ${ }^{16}$. Apontam dois tipos de avaliação cognitiva: primária e secundária. Durante a avaliação primária é levado em consideração a repercussão do evento para a pessoa e se a mesma está correndo risco no agora ou no futuro, e de que forma. $\mathrm{Na}$ avaliação secundária, é a avaliação do que pode ser feito para enfrentar o evento ${ }^{16}$.

Destaca-se também a importância de um preparo emocional do psicólogo durante a situação de emergências e desastres. Não se pode esquecer que a figura 
do psicólogo nessas situações é o controle emocional mesmo que a situação seja caótica ${ }^{6}$.

A psicologia das emergências tem por objetivo estudar o comportamento humano nos acidentes e nos desastres tantos ambientais como causados pelo homem, desde a ação preventiva ao pós trauma, podendo atender as necessidades das vítimas do trauma e aos socorristas ${ }^{6,17}$.

No que se refere ao atendimento inicial ou a atuação durante as emergências e desastres o psicólogo que atua nesta área é visto como um serviço dispensável diante da gravidade dos fatos.

Mas, esse cenário vem mudando mediante ao trabalho positivo que vem sendo realizado. A diferença dos atendimentos é totalmente oposta do que se via do psicólogo até então, o psicólogo que atua em emergências tem que estar preparado para atender a vítima do desastre no local do acidente 6 .

A finalidade do trabalho do psicólogo não se restringe apenas no momento da emergência, mas, também realizará um trabalho com a família vítima do desastre a adaptação da nova realidade.

Nesse processo percebe-se a grande diferença do atendimento clínico para o emergencial. De acordo com a experiência da autora pequenas coisas que não fariam sentido num consultório fazem grande sentido na emergência. Como por exemplo: O psicólogo aconselha à pessoa afetada a trocar de roupa, caso a roupa esteja suja ou molhada, por causa do evento, para tirar a pessoa do estado de mais um figurante da cena caótica. O psicólogo também se certifica de que a pessoa bebeu água, se alimentou se está com frio ou com calor, o que normalmente não acontece num consultório ${ }^{6}$.

Assim, estas atitudes podem ser o início da reorganização dessa pessoa frente a tragédia, emergência ou desastre enfrentado.

A atuação do psicólogo tem ocorrido, na maioria das vezes, no pós desastre, porém, o ideal seria que também a sua presença cada vez mais se efetivasse no trabalho para a prevenção dos desastres.

Em Santa Catarina juntamente com o estado do Rio Grande do Sul, foi fundado um projeto que tem por título: Prevenção de Emergências; construindo comunidades mais seguras. Este projeto tem como principal objetivo contribuir para o 
fortalecimento da sociedade civil através do envolvimento das comunidades, dos movimentos e organizações sociais e das instâncias públicas locais, para atuação eficaz na implantação de políticas públicas de prevenção de riscos ambientais e nas situações de emergências.

Este projeto foi elaborado por pessoas da própria comunidade e por órgãos colaboradores do Rio Grande do Sul e Santa Catarina.

Até o final da construção deste artigo não foi publicada a participação de nenhum profissional da psicologia juntamente com esta equipe, o que seria uma grande oportunidade para adquirir maior conhecimento sobre o tema e também levar as contribuições da área da psicologia.

\section{HISTÓRICO DA DEFESA CIVIL NO ESTADO DE SANTA CATARINA}

Foi a partir da Segunda Guerra Mundial, que foi instalado no Brasil os princípios básicos da Defesa Civil, visando a segurança da população, o governo cria em 1942, o Serviço de Defesa Passiva Antiaérea e a obrigatoriedade do ensino da defesa passiva em todos os estabelecimentos do ensino. No ano seguinte, a denominação de Defesa Passiva Antiaérea passa a ser chamada de Serviço de Defesa Civil.

Com as ocorrências de fenômenos cíclicos, no Estado de Guanabara em 1966, organizou-se um grupo de Trabalho com a finalidade estudar a mobilização de vários órgãos estaduais em casos de catástrofes. Este grupo fundou o Plano Diretor de Defesa Civil do Estado de Guanabara. O Decreto Estadual ํo 722, de 18 de Novembro de 1966, aprovou este plano e estabeleceu a criação das primeiras Coordenadorias Regionais de Defesa Civil - REDEC, A partir deste feito foi fundada a primeira Defesa Civil Estadual do Brasil.

No Estado de Santa Catarina a Lei № 4.841 de 18 de maio de 1973 cria a Defesa Civil Estadual, sendo esta vinculada ao Gabinete da Casa Civil. Em setembro de 1988 o Sistema de Defesa Civil foi reeditado através da Lei no 10.925 que dispõe sobre o Sistema de Defesa Civil - SIEDC, sobre o Fundo Estadual de Defesa Civil FUNDEC. 
Com o avanço das ações de Defesa Civil, ela deixa de ser apenas um órgão que trabalha apenas em resposta às situações de emergências e calamidades, começa a atuar nas formas de prevenção e reconstrução das áreas afetadas. Assim, em cumprimento ao artigo 21, inciso XVIII, da Constituição Federal de 1988: "planejar e promover a defesa permanente contra as calamidades públicas, especialmente as secas e as inundações", foi criado pelo Governo Federal o Sistema Nacional de Defesa Civil (SINDEC).

Inicialmente o SINDEC foi instituído pelo Decreto №. 895, de 16 de agosto de 1993. Tal dispositivo foi revogado pelo Decreto Federal no. 5.376 de 17 de fevereiro de 2005. O SINDEC tem por objetivo planejar e promover a defesa contra desastres naturais, antropogênicos e mistos, de maior prevalência no País. As demais funções do SINDEC está na promoção, prevenção, assistência, reabilitação e em qualquer outra circunstância de desastres.

No Brasil, culturalmente as ações são tomadas durante ou após os desastres, as medidas de prevenção ainda não são priorizadas. Pensando nisso, o Departamento Estadual de Defesa Civil, está investindo em medidas preventivas. $O$ Governo Federal de Santa Catarina, juntamente com outros órgãos responsáveis e com a Universidade Federal de Santa Catarina, criou um Atlas de Desastres Naturais de Santa Catarina; Mapa de Suscetibilidade a Risco de deslizamento e Enchentes na Bacia do Rio Itajaí; apostilas, cursos de capacitação, entre outros.

Segundo o IBGE, Santa Catarina tem a população estimada em 6.819,190 habitantes, dados atualizados em 2015. Os últimos acontecimentos de mudanças climáticas em Santa Catarina, tem repercutido por muitos jornais e mídias no país todo, algumas dessas caracterizadas são: deslizamentos, enchentes, inundações, deixando um grande número de desabrigados e mortos. As estiagens prolongadas também acabam prejudicando a agricultura e a pecuária.

O Manual de Defesa Civil ainda destaca que nas últimas quatro décadas ocorreram desastres que deixaram grandes marcas na nossa história; ao todo foram mais de 400 mortes e cerca de 650 mil pessoas ficaram desabrigadas.

O desastre mais trágico ocorreu em 1974, na cidade de Tubarão, a cidade foi invadida pela água que subiu mais de 10 metros resultando na morte de 199 pessoas e 65 mil desalojados/desabrigados. 
Diante dessas informações é sempre bom lembrar qual a missão da Defesa Civil segundo a Doutrina Nacional de Defesa Civil é um "Conjunto de ações preventivas, de socorro, assistenciais e reconstrutivas, destinadas a evitar ou minimizar os desastres, preservar a moral da população e restabelecer a normalidade social”21.

A Defesa Civil é responsável por elaborar os Planos de preparação, nesse caso, juntamente com a comunidade, preparar equipes de atendimento, equipes de apoio, de assistência e reconstrução. Lembrando que o objetivo maior para a preparação as emergências e desastres é a prevenção da situação de risco.

Em nosso município a Defesa Civil está sempre em pronto atendimento para receber e dar informações sobre qualquer risco de temporais, alagamentos e possíveis desastres. A defesa Civil de Criciúma/SC faz parte da Cidade Resiliente, um programa do Governo Federal onde participa a cidade que tem condições de resistir, absorver e se recuperar de forma eficiente dos efeitos de um desastre e de maneira organizada prevenir que vidas e bens sejam perdidos ${ }^{21}$.

O plano de ação em Santa Catarina se dá através de uma construção e todo planejamento é feito um treinamento antes. Para evitar falhas durante a execução. As ações se dividem em duas etapas: Sair da situação onde ocorreu o sinistro, ou seja, retirar a população do lugar afetado ou isolar o lugar, prestar atendimento médico quando necessário, entre outros. A segunda etapa seria 0 suporte a população afetada. Com assistência básica de água, comida, roupa, cadastros, e no que for necessário para agilizar o processo de "normalidade".

Nas pesquisas bibliográficas feitas para o presente artigo, não foi encontrado registros de profissionais da psicologia atuando junto á defesa civil.

A Defesa Civil trabalha numa atuação mais prática, ou seja, as etapas do seu planejamento são: prestar socorro, que tem por objetivo tirar a pessoa do local de risco. Assistência humanitária, colocar essas pessoas em abrigos, e oferecer cuidados básicos como alimentos, água, remédios e outros. Reabilitação, a reabilitação está voltada para área afetada pelo desastre ${ }^{21}$.

No que se refere ao atendimento à pessoa vítima do desastre e ao comportamento da mesma diante do ocorrido, ainda é algo muito recente. No entanto 
este movimento vem crescendo cada vez mais, e já se fala sobre a importância da atuação do psicólogo nesta área da psicologia das emergências e desastres.

Um dos sintomas do Transtorno de Estresse Pós Traumático (TEPT) é a lembrança automática do acontecimento, reviver o evento traumático, causando medo, ansiedade, depressão, isolamento, entre outros problemas fisiológicos. Acredita-se que é fundamental a participação do psicólogo junto à defesa civil e em todos os âmbitos que envolvem a situação de desastre e emergência, bem como em campanhas de prevenção, assim também contribuindo para a promoção da saúde mental e emocional da população.

\section{CONCLUSÃO}

A atuação do psicólogo frente a situações de Emergências e Desastres tem sido tema de muitos trabalhos na atualidade.

Considerando a relevância deste tema, observa-se que os desastres naturais ocorridos no Estado de Santa Catarina à nível de Brasil e regional e o aquecimento global que estão vinculados às intervenções humanas, vêm causando preocupações a nível mundial, não apenas no que diz respeito à reconstrução do lugar afetado, preservação da natureza, mas especialmente a reconstrução da identidade dos envolvidos.

Assim este estudo pretendeu explorar o papel do psicólogo nas situações de emergência ou desastre e sua inserção junto à órgãos que partem em resposta quanto tais situações ocorrem.

Como achados deste estudo encontrou-se que o psicólogo ainda não está inserido obrigatoriamente na equipe da Defesa Civil. A sua inclusão nesta equipe seria de fundamental importância para que houvesse maior eficácia na prestação de serviços à comunidade, colaborando tanto para atuação com as vítimas do desastre quanto para a equipe em si,no pré e pós desastre.

Pode-se perceber através das leituras realizadas a necessidade da inclusão do profissional da Psicologia especialmente junto à Defesa Civil, pelo seu caráter de órgão que prontamente chega até as vítimas.

Porém, pode-se também constatar que a inclusão do psicólogo depende 
das políticas públicas, e da compreensão tanto da comunidade de seu importante papel, em todas as instâncias relacionadas aos desastres e situações de emergência,quanto da classe profissional a luta pelo reconhecimento da necessidade do profissional nesta área de atuação.

Com base nos estudos de Gonçalves ${ }^{8}$ frente a estas situações o psicólogo também tem um importante papel no trabalho com a identidade de lugar das vítimas envolvidas, quesofrem grandes repercussões ao longo da vida, tanto no plano simbólico quanto no plano concreto, os efeitos de num desastre não são os mesma para todos.

O comerciante, por exemplo, sofre com a dor que passou com a perda de suas mercadorias; uma dona de casa, na destruição de sua moradia; uma criança, na perda de seus brinquedos e de amiguinhos falecidos no evento; um idoso, na perda de seus objetos de valor sentimental que traduzem uma trajetória de vida; para um agricultor, com a devastação da lavoura ${ }^{22}$.

De modo geral, há um compromisso social dos psicólogos sobre os indivíduos que estão sendo acolhidos, que ocorrem por meio do olhar crítico, ético e político. Nesse sentido, os psicólogos atuam visando a garantia dos direitos humanos.

Observamos que em meio a inúmeras técnicas disponíveis para a realização do atendimento a estas vítimas, a principal ação exercida é o acolhimento, deixando as técnicas e abordagens específicas "de lado", permitindo-se estar próximo e em contato com a dor e a realidade do outro.

Também compreendeu-se que a atuação do psicólogo na etapa de prevenção é fundamental, e este tem muito à contribuir em trabalhos de informação e sensibilização junto a comunidade.

Finalizando a área da Psicologia em situação de desastre e emergência, torna-se muito relevante no cenário atual, pela situação de risco eminente associada pela crise ambiental criada pela "mão" do próprio homem. As projeções não são nada promissoras quanto ao retorno a um equilíbrio, ahumanidade encontra-se em situação de vulnerabilidade e a Psicologia diante deste cenário precisa também posicionar-se e buscar respostas e alternativas.

\section{REFERÊNCIA}

Revista Inova Saúde, Criciúma, vol. 9, n. 2, jul. 2019.

ISSN 2317-2460 
1 - Fernandes L. Santa Catarina é o terceiro estado mais atingido por desastres naturais. [internet] 2013 [acesso em 2016 maio 15]. Disponível em: http://portaljoinville.com.br/noticias/2013/06/sc-e-o-terceiro-estado-mais-atingido-pordesastres-naturais

2 - G1. Dez anos após o furacão Catarina, moradores relembram a tragédia. [internet] 2014 [acesso em 2016 maio 15]. Disponível em: g1.globo.com/sc/santacatarina/noticia/2014/03/dez-anos-apos-o-furacao-catarina-moradores-relembramtragedia.html

3 - Herrmann MLP. Atlas de Desastres Naturais do Estado de Santa Catarina. 2a ed. Florianópolis: Sea/dged, 2007. 136 p.

4 - American Psychiatric Association. DSM-IV. Manual Diagnóstico e Estatístico de Transtornos Mentais. 4a ed. Porto Alegre : Artmed, 2002.

5 - Molina R. Mesa-redonda Mesa: A Psicologia das Emergências e Desastres e compromisso social: a experiência latino-americana. Conselho Federal de Psicologia. 2011. 100p

6 - Franco MHP. A Intervenção Psicológica em Emergências: Fundamentos para a prática. Rio de Janeiro: Summus, 2015. 236 p.

7 - Lewin KC. Group decision and social change. In: Newcamb, TM, Hantley, EL. Readings in Social Psychology. New York: Holt, Dinehart \& Winston, 1947.

8 - Gonçalves TM. Cidade e Poética: um estudo de psicologia ambiental sobre o ambiente humano. ljuí: Unijuí, 2007. 208 p.

9 - Gregio C. Antes e depois do trauma: vivência traumática e o mundo presumido. [Dissertação]. [São Paulo]: Pontifícia Universidade Católica de São Paulo, 2005. 
10 - Reyes G, Jacobs GA. Handbook of international disaster psychology. Fundamentals and overview. Westport: Praeger, 2006.

11 - Fávero E, Diesel V. "A seca enquanto um hazard e um desastre: uma revisão teórica". Aletheia. 2008. 27:198-209.

12 - Greenstone JL. The elements of disaster psychology. Managing psychosocial trauma. An integrated approach to force protection and acute care. Springfield: Charles Thomas Publisher , 2008.

13 - Torlai VC. A vivência do luto em situações de desastres naturais. [Dissertação]. [São Paulo]: Pontifícia Universidade Católica de São Paulo, 2010.

14 - Conselho Federal de Psicologia. Código de Ética Profissional do Psicólogo. [internet]. Brasília: CFP, 2005 [acesso 2016 jun. 2]. Disponível em: http://www.pol.org.br/pol/cms/pol/legislacao/codigo_etica

15 - Melo CA, Santos FA. As contribuições da psicologia nas emergências e desastres. Psi Infor. 2011;15(15):169-81

16 - Coêlho AEL. A psicologia em situações de emergências e desastres. Psicologia e Direitos Humanos. 2010. No prelo.

17 - Bruck NRV. A Psicologia das Emergências: Um estudo sobre angústia pública e o dramático cotidiano do trauma. [Tese]. [Porto Alegre]: Pontifícia Universidade Católica do Rio Grande do Sul, 2007. 195 p.

18 - Lane STM, Godo W. Psicologia social: o homem em movimento. 13a ed. São Paulo: Ed. Brasiliense, 1997. 220 p.

19 - Bock AMB, Furtado O, Teixeira MLT. Psicologias uma introdução ao estudo de Revista Inova Saúde, Criciúma, vol. 9, n. 2, jul. 2019. 
psicologia. 12ª ed. São Paulo: Saraiva, 2002. 319 p.

20 - Paranhos ME, Werlang BSG. Psicologia nas Emergências: Uma Nova Prática de Ser Discutida. Psicol. Cienc. DOI http://dx.doi.org/10.1590/1982-370301202012.

21 - Conselho Federal de Psicologia. Emergências e desastres: nota técnica sobre atuação de psicóloga (o)s em situações de emergências e desastres, relacionadas com a política de defesa civil [internet]. Brasília; 2013 [acesso em 2016 jun 2]. Disponível em: http://site.cfp.org.br/emergencias-e-desastres-2.

22 - Valêncio N. Mesa-redonda Mesa: A sociologia dos desastres: perspectivas para uma sociedade de direitos. São Paulo: Conselho Federal de Psicologia, 2011. 